\title{
Chapter 12 \\ Socially Open-Ended Problems \\ for Enriching Student Learning \\ with Mathematical Models and Social \\ Values
}

\section{Takuya Baba and Isao Shimada}

\begin{abstract}
Our society is increasingly dependent on technologies such as in the life sciences and information technologies. The technologies create alternatives and the choice among alternatives is guided by what the individual values. On the other hand, Bishop (1991) pointed out the danger that the general public and students understand that mathematics learning is regarded in many countries as being unreal and value-free, mainly because of the abstract nature of mathematics. This gap between social reality and students' perceptions deprives many students of a willingness and positive attitudes towards problem-solving in mathematics. This chapter proposes a new approach to dealing with social values through problem-solving. Baba (2007, 2009) has named this type of problem "socially open-ended problem" which elicits students' social values by extending a traditional open-ended approach (Shimada 1977). This chapter describes some basic ideas and discusses how the social values are treated while dealing with socially open-ended problems.
\end{abstract}

Keywords Socially open-ended problem $\cdot$ Mathematical models $\cdot$ Social values Problem-solving

\subsection{Historical Background and Research Aim}

Since the 1980 declaration of the US National Council of Teachers of Mathematics (NCTM), problem-solving has occupied the core of mathematics education. Some key ideas such as meta-cognition and problem-solving strategies have been developed through research (Schoenfeld 1983). On the other hand, Lesh and Zawojewski (2004) pointed out limitations in the research on strategies and proposed Model-Eliciting Activities (MEA) as a new approach to these limitations. MEA and problem-solving

\footnotetext{
T. Baba $(\bowtie)$

Hiroshima University, 1-5-1, Kagamiyama, Higashi-Hiroshima, Hiroshima 739-8529, Japan e-mail: takuba@hiroshima-u.ac.jp

I. Shimada

Nippon Sport Science University, Setagaya, Japan

e-mail: shimadaisao@nittai.ac.jp 
look very similar. MEA emphasizes developing mathematical models from phenomena. It not only places emphasis on finding the solution to the problem but also on deeply understanding the phenomenon through the mathematical model. Here, solving the problem forms part of the MEA, but it is not all of it. This is a similar idea to the mathematization cycle within the OECD definition of mathematical literacy. But they are slightly different as well. As the words suggest, a model-eliciting activity has more of a focus on the process, whereas mathematical literacy places more stress on the children's ability to interpret the world.

Before moving further, we first review historically problem-solving in the Japanese context. In Japanese mathematics education, problem-solving has been developing in a unique way. After World War II, a US education mission was dispatched to Japan in order to prescribe the education system for post-war Japan. It recommended Life-Unit Learning (LUL) based on John Dewey's philosophy. In LUL, a problem means something in our daily life. For example, weeding in the field was used as introductory material to teach multiplication of a fraction by an integer in Grade 6 (Toda 1953). Here the portion of a rice field which can be weeded in a day was given. Then children were asked to calculate how many days were necessary to finish weeding the whole rice field. The purpose of problem solving was to use the context of daily life as introductory material to teach concepts of number, quantity, and shape and to develop the ability to consider and treat the phenomenon and scientific attitudes in daily life (Ministry of Education, Science and Culture 1947). Here, daily life explicitly appeared in problems. (In this chapter we use this characteristic but called it the "sociality" of problem-solving.) The word and concept of "mathematization", which refers to the process of developing a mathematical model from the daily life context, finding the solution, and interpreting the solution in the context, was yet to be developed.

The LUL was not a continuation of the mathematics education in the pre-war period, but rather was brought from the outside, as noted above, from the US. In addition, a decline in mathematics achievement in primary school was pointed out during this period (Kubo 1951). LUL was criticized as the cause of the poor level of achievement. Instead, a new curriculum called Systematic Learning (SL) was introduced to lead students to an understanding of basic concepts and principles of number, quantity and shapes, and to develop more advanced mathematical thinking and treatment (Ministry of Education, Science and Culture 1958). It was during this time that "mathematical thinking", the pillar of mathematics education in Japan, was introduced in the objectives of the Course of Sutdy. This shift from LUL to SL had a long-term effect on mathematics education in Japan.

The open-ended approach (Shimada 1977; English translation, Becker and Shimada 1997) started as a project headed by a team of professors and school teachers, who developed and intensively employed open-ended problems, in order to evaluate this mathematical thinking. The open characteristic of the problems stimulated children to produce various solutions and to pay attention to mathematical structures embedded in those solutions. These characteristics attracted attention from many researchers and practitioners all over Japan. It later became a teaching method to develop mathematical thinking. 
In Japan, due to the experience of LUL, the term "problem solving" was avoided for some time. In the 1980s, when the results of the SIMS (Second International Mathematics Survey) were released, it was pointed out that Japanese students had attained very high achievements in general but relatively low achievements in nonroutine word problems (National Institute for Education Research 1991).

Coincidentally, around the same time, the NCTM declared the 1980s to be the decade for problem-solving. This situation caused the Japanese mathematics education community to discuss the interpretation of this movement, because of its previous experience, and coined the new word "Learning Through Problem Solving" (LTPS) (Ministry of Education, Science and Culture 1989) to differentiate it from the previous problem-solving in the LUL period. Naturally, it continued to emphasize higher-order mathematical thinking, through LTPS using non-routine problems rather than simply solving a problem. In this sense, mathematical thinking is the persistent hope of the Japanese mathematics education community (Ueda et al. 2015). Since mathematical thinking emphasizes mathematical structure found in various solutions to the open-ended problem, this characteristic in SL and LTPS is called the "mathematicality" of the problem-solving.

We have so far reviewed some of the major events in the history of mathematics education in post-war Japan and noted the trend from LUL to SL and then to LTPS. The first put more emphasis on the daily life context as introductory material and had a tendency to have less emphasis on mathematics. The second (SL) and its successor LTPS puts more emphasis on recognition of mathematical structures and has a tendency to take the daily life context lightly. In summary, problem-solving and the problems considered have shifted from the "sociality" of the problem solving (the daily life context) to the "mathematicality" of the problem solving (the mathematical structure). Interestingly PISA has proposed mathematical literacy and more contextual problems (OECD 2013). However, in Japan, problems have had a greater inclination towards mathematical structure and structural thinking than towards social reality until recently because of the historical background outlined above.

\subsection{Socially Open-Ended Problems}

Since the 2000s, international comparative surveys of education such as TIMSS and PISA have been conducted regularly. A new type of problem-solving has been proposed as a part of the PISA study. The "problem" in the PISA study is overwhelmingly long and very contextual. The context seems to provide very authentic situations to the students (Palm 2008). Like MEA, problems in PISA studies ask students not only to find the mathematical solution but also a solution strategy which involves a series of processes such as moving back and forth between the mathematical world and real world, and hence finding a mathematical solution and its interpretation in a real world context. Here the ability required is termed mathematical literacy. Its definition is given as follows: 
an individual's capacity to formulate, employ, and interpret mathematics in a variety of contexts. It includes reasoning mathematically and using mathematical concepts, procedures, facts, and tools to describe, explain, and predict phenomena. It assists individuals to recognize the role that mathematics plays in the world and to make the well-founded judgments and decisions needed by constructive, engaged and reflective citizens (OECD 2013, p. 17).

In order to characterize mathematical literacy in the Japanese context, it is important to revisit the experience of problem-solving in Japan. After LUL, the openended approach has become the teaching approach in Japan to enhance mathematical thinking to consider structurally various solutions and to find the commonness and invariance among them in open-ended problems (Shimada 1977; English translation, Becker and Shimada 1997). Here Nakajima (1981), who was a leader of research on mathematical thinking, stated "Mathematics is said to hold three characteristics (abstractness, logicalness and formality). These characteristics have been naturally formed as a historical pursuit based on certain values. And these values, which form a foundation of three characteristics, are pointed out .... conscience, clarity and integration" (p. 56). He explained further that two of these values, conscience and clarity, started appearing in the Course of Study (1953), and they were refined and stated in the next Course of Study (1968) by adding integration as a source of creativity. Thus for Nakajima, the mathematical values of conscience, clarity and integration, are embedded within the nature of mathematics.

On the other hand, Iida et al. (1994) discovered that moral issues or ethical values might occur in the process of researching the open-ended approach when students deal with such topics as melon division ${ }^{1}$ and room assignment. ${ }^{2}$ More recently, Greer (2007) has pointed out that the mathematical modelling for proportion problems prompts recognition of equity. These findings indicates division in the real world may create issues related to ethical issues.

So far, we have seen two types of values. One consists of mathematical values, which are related to mathematical structures such as clarity and integration. The other is social values such as equity and fairness. Here our interpretation is that mathematical literacy and full contextuality of PISA problems may have the potential to integrate the two types of values. This is a new dimension of problem-solving, which is different from LUL, SL and LTPS.

The world currently faces global problems such as environmental issues and poverty issues, and individuals in a society also face personal problems such as conflict management and medical considerations. Since these problems are multifaceted due to technological advancement and the globalized economy, their resolution can have various alternatives, one of which may be chosen according to values. These problems are called trans-science problems, in which science and politics interact, and cannot be solved only scientifically (Kobayashi 2007). Perhaps the perfect resolution is not possible. For example, the problem whether we should maintain nuclear

\footnotetext{
1 "Melon division" provides a situation where 10 melons as a prize in a game are to be divided among three teams and the scores for each team are given.

2 "Room assignment" provides a situation where 10 students are to be assigned to 4 rooms of different sizes during an excursion.
} 
Table 12.1 Comparison of two types of open-ended problems (Baba 2007, p. 22)

\begin{tabular}{|c|c|c|}
\hline & Mathematically open-ended problem & Socially open-ended problem \\
\hline Objective & To nurture mathematical thinking & $\begin{array}{l}\text { To nurture mathematical thinking and } \\
\text { judgement based on mathematical } \\
\text { thinking and associated social values }\end{array}$ \\
\hline Problem & $\begin{array}{l}\text { To allow mathematically diverse } \\
\text { solutions }\end{array}$ & $\begin{array}{l}\text { To allow mathematically diverse } \\
\text { solutions and associated social values }\end{array}$ \\
\hline Method & $\begin{array}{l}\text { Discussion on mathematically diverse } \\
\text { solutions and their generalization and } \\
\text { symbolization }\end{array}$ & $\begin{array}{l}\text { Discussion on mathematically diverse } \\
\text { solutions and the associated social } \\
\text { values }\end{array}$ \\
\hline
\end{tabular}

power plants for energy requirement in the society cannot be solved only through technological solution.

Despite these necessities of our current society, Bishop (1991) pointed out the general public and students understand that mathematics problem solving is regarded in many countries as being unreal and value-free, mainly because of the abstract nature of mathematics (Skovsmose 1994). Since it is values that have impact on students' lasting impressions of their school mathematical experiences (Clarkson et al. 2001), the lack of positive attitudes towards mathematics learning may have an impact on individual ability and thus society's ability as a whole to solve such problems as noted above.

From these considerations, we propose a pedagogical approach for dealing with problems that can be encountered in daily life and that involves some social values in their solutions. Here this type of problem is called a socially open-ended problem (Baba 2007, 2009), because it provides different mathematical models for a solution like the traditional open-ended problems and also the social values which go together with the models. Thus employing the classification of openness (Hashimoto 2007), this approach contains open process and open-end product. This prompts a new pedagogical approach because teachers have a choice in that they may use the social values appearing in the mathematical models. So far, teachers usually have avoided dealing with social values, seeing them as noise in mathematics teaching, and regarding them as unnecessary to understanding mathematics concepts (Iida et al. 1994). Our proposal, however, is that a mathematics lesson can be enriched with social values, and thus the mathematicality and sociality of problem-solving are integrated into this approach.

We will now make a comparison between the traditional open-ended approach and the proposed pedagogical approach with socially open-ended problems. Whereas the traditional open-ended approach focuses mainly on mathematical aspects of problems, the socially open-ended problems approach utilizes both mathematical solutions and their associated social values to nurture judgement based on them (see Table 12.1 for a tabulated comparison). 
At a school cultural festival, your class offers a game of hitting a target with three balls. If the total score is more than 13 points, you can choose three favorite gifts. If you score 10 to 12 points, you get two prizes, and if you score 3 to 9 points, you get only one prize. A first grader threw a ball three times and hit the target in the 5-point area, the 3-point area, and on the border between the 3-point and 1-point areas.

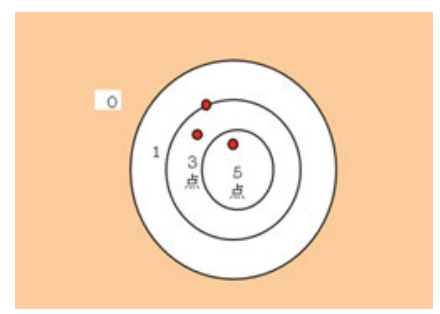
How do you give the score to the student?

Fig. 12.1 Socially open-ended problem (Matoate)

\subsection{Lesson Using a Socially Open-Ended Problem}

We now consider an example of a socially open-ended problem for further discussion. The authors have developed one of the socially open-ended problems, "Matoate" (hitting the target, see Fig. 12.1) (Shimada and Baba 2012, 2016). This problem was given to 38 students, comprising 19 boys and 19 girls. The second author, who taught this lesson is a teacher who specializes in mathematics education, and has 40 years of teaching experience at the time.

The lesson was carried out with fourth graders in a private elementary school in Tokyo in March 2013. Since this is a pedagogical approach, it is essential to describe not only the problem but also the teacher's interventions and interactions with students during the lesson process. In this lesson, the above problem was first presented to the students. They were then expected to work individually to find a solution to the problem and the reasons for their solution. The reason given should contain a social value(s), which was associated with their solution. After the individual work, the teacher facilitated the classroom discussion among students regarding solutions as mathematical models, and the associated social values. Sometimes such social values were not explicit at first and only became explicit after the interaction. At the end of the lesson, the students were asked again to choose mathematical models and recognize the social values in the solution process.

Through the lesson the teacher was on the look out for any students who modified their mathematical models and/or changed their choice of social values, which were called transformation of social values. If this did occur, such transformations were to be ascertained through a comparison between the values at the beginning of the lesson and those at the end. 


\subsubsection{Beginning Stage of the Lesson}

At the beginning stage of the lesson, the students were given the above problem and asked to write their solutions with reasons. There were two types of values that were identified, namely, equality among the whole participants and priority to a specific person (Nagasaki et al. 2008).

(Protocol [1] of "Matoate" (hitting the target)) (T stands for a teacher and S stands for a student.)

\begin{tabular}{l|l}
\hline T1: & So, please think about this problem and also write the reason \\
\hline & $\begin{array}{l}\text { After students worked on the problem individually for } 10 \text { min, discussion started on } \\
\text { different ideas }\end{array}$ \\
\hline S1: & $\begin{array}{l}\text { The first grader might be happy to get the bigger score because the ball is between the } \\
\text { 1-point area and the 3-point area. They can get two prizes because } 5+3+3=11\end{array}$ \\
\hline S2: & $5+3+(3+1)=12$. Since it is a first grader, both points would be given \\
\hline T2: & $\begin{array}{l}\text { That's a great service to give both points when the ball is on the borderline between two } \\
\text { areas. It is very kind of you to a small child }\end{array}$ \\
\hline
\end{tabular}

In the dialog above, S1 made a decision to give the higher score, but S2 went further and suggested giving both scores, when the ball was on the border of two areas in the target. These answers showed the social values of the students to care for the first grader. They also developed the mathematical models, S1 giving the higher score $(5+3+3)$, and S2 adding both points $(5+3+3+1)$. As can be seen, different mathematical models can be made based on the same social value "kindness" (to the first grader).

\subsubsection{The Development Stage of the Lesson}

The lesson progressed with the teacher asking for more discussion on the various solutions that the class had developed. During this process, one social value was observed more explicitly ("kindness to a specific person"), while the other social value ("fairness and equality to the whole") stayed rather implicit (see Table 12.2).

This becomes evident in the following discussion:

\begin{tabular}{l|l}
\hline T3: & So, please make a presentation on how you think about this problem. S.J., please \\
\hline S.J.1: & $\begin{array}{l}\text { I gave } 3 \text { points to the first grader, so I wrote } 5+(3 \times 2)=11,11 \text { points, because the } \\
\text { first grader should be welcomed (Fig. 12.2) }\end{array}$ \\
\hline
\end{tabular}


(continued)

\begin{tabular}{l|l}
\hline T4: & Does anyone have any questions for S.J.? \\
\hline S4: & $\begin{array}{l}\text { I think that we do not have to write parentheses in the expression because we calculate } \\
\text { the multiplication before the addition }\end{array}$ \\
\hline S.J.2: & Thank you, I understand. I will rewrite it as $5+3 \times 2=11$ \\
\hline T5: & And who did you think of, S.J.? \\
\hline S.J.3: & I thought of the first grader \\
\hline T6: & $\begin{array}{l}\text { I will write the words "kindness to the first grader" next to the S.J.'s idea. Next, please } \\
\text { present your idea, K.K. }\end{array}$ \\
\hline K.K.1: & $\begin{array}{l}\text { The ball is on the boundary of } 3 \text { points and 1 point. I give 1 point because the 1-point } \\
\text { area of the ball is larger than the 3-point area of the ball. So, 1 + 3 + 5 = 9, 9 points } \\
\text { (Fig. } 12.3)\end{array}$ \\
\hline T7: & Does anyone have any questions for K.K.? \\
\hline S5: & $\begin{array}{l}\text { What points will you give to the first grader when the ball reaches the middle just } \\
\text { above the line? }\end{array}$ \\
\hline K.K.2: & I will give 2 points \\
\hline S6: & $\begin{array}{l}\text { What points will you give to the first grader when the ball reaches the middle of just } \\
\text { above the line of } 1 \text { point and } 0 \text { point? }\end{array}$ \\
\hline K.K.3: & I will give 0.5 points \\
\hline T8: & S.J. gave 3 points to the first grader. And who did you think of, K.K.? \\
\hline K.K.4: & I thought about all the people who play the game. I want to be impartial to all people \\
\hline T9: & So I will write the words "fairness to all people" next to K.K.'s idea \\
\hline & \\
\hline
\end{tabular}

In the interaction, kindness to the first grader appears rather easily, but fairness to all the participants can appear only when a comparison is made. Explicitness and implicitness of the social values are also manifested in Table 12.2. For example, for the mathematical model "a. $5+3+3$ ", $92.9 \%$ of students wrote reasons representing

Table 12.2 Students' mathematical models and associated social values at the beginning stage $(\mathrm{N}=38)$

\begin{tabular}{|c|c|c|}
\hline Mathematical models & Associated social values & $\begin{array}{l}\text { Percentage of explicit social } \\
\text { values }\end{array}$ \\
\hline a. $5+3+3$ & \multirow{4}{*}{$\begin{array}{l}\text { Kindness to the first grader } \\
\text { (specific person) }\end{array}$} & $92.9(13 / 14)$ \\
\hline b. $5+3+(3+1)$ & & $100.0(1 / 1)$ \\
\hline c. $5+3+3+1+1$ & & $100.0(1 / 1)$ \\
\hline d. $5+3+2$ & & $100.0(2 / 2)$ \\
\hline e. $5+3+2$ & \multirow{3}{*}{$\begin{array}{l}\text { Fairness and equality to the } \\
\text { whole participant (all students) }\end{array}$} & $0.0(0 / 9)$ \\
\hline f. $5+3+1$ & & $0.0(0 / 10)$ \\
\hline g. $5+3+3$ & & $0.0(0 / 1)$ \\
\hline
\end{tabular}

Note In the column for the percentage of explicit social values, the fractions in parenthesis showed the number of students who wrote a particular mathematical model and expressed the social values explicitly against the total number of students who wrote a particular mathematical model 
Fig. 12.2 S.J.'s presentation

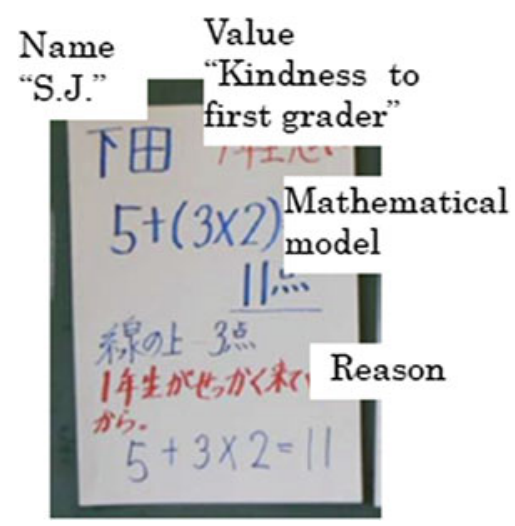

Fig. 12.3 K.K.'s

presentation

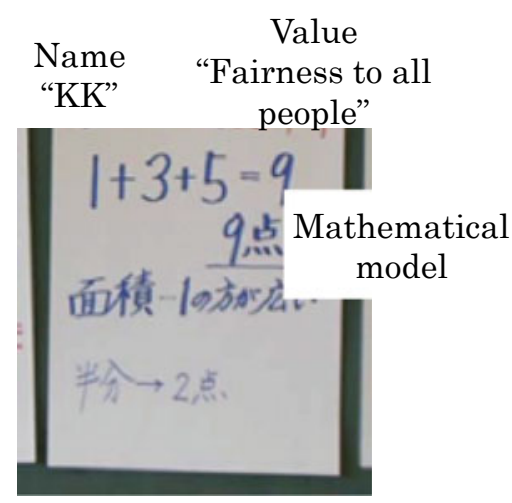

social values. The interaction gives an impression that they seem to be conscious of these values and even recalling the days when they were at first grade.

The reason why fairness and equality are rather latent may be that it is too obvious for the students to think about all the participants as a whole. Therefore, until some critical moment arrives, they do not pay much attention to those obvious values such as fairness and equality. In the above lesson, the students had a critical moment by being asked "who do you think of..." in comparison with "kindness to the first grader". We think that it is important to nurture understanding and appreciation of both social values in a democratic society. 


\subsubsection{The Summary Stage of the Lesson}

After discussion in the classroom, students were asked to select one model and to write down the reason. Students seemed to have been influenced by the class discussion and revised their mathematical models and transformed associated social values. These are shown in Table 12.3.

Table 12.3 is a cross-tabulation showing the relationship between the social values at the beginning and the summary stages of the lesson. Interestingly, the percentage of students who selected different social values at each stage, and thus transformation of mathematics is about one-third of students $(15.8+15.8=31.6 \%)$.

Table 12.4 shows the reasons why the six students $(15.8 \%)$ who selected the social value of "fairness and equality" at the beginning stage, then changed their choice at the summary stage. Half of these students (U.K., T.M. and N.M.) supported K.U.'s idea which was " $1+3=4,5+3=8,8+4=12,12+1=13$. I'll give 4 points combining 1 point and 3 points for the first grader. I give 1 point with a further bonus". Appreciating this idea, U.K. said, "The first grader will be happy and come here again." On the other hand, K.U. himself transformed his idea to the idea of T.R. which at the summary stage was given as " $5+3=8,(1+3) \div 2=2,8+2=10$. The ball is on the boundary of 3 and 1 . It is 4 by adding 1 and 3, and then becomes 2 by dividing 4 by 2 . It becomes 10 when I add 8 and 2". K.U. transformed his social value after knowing the other student's social value of "fairness and equality," and stated, "I think that it is nice to give 2 points because of equality."

Table 12.3 Percentage of students in class who choose associated social values at the beginning and summary stages of the lesson

\begin{tabular}{l|l|l|l|l}
\hline & & \multicolumn{3}{|l}{ Associated values at the summary stage } \\
\cline { 3 - 5 } & $\begin{array}{l}\text { Fairness and } \\
\text { equality }\end{array}$ & $\begin{array}{l}\text { Kindness to the } \\
\text { first grader }\end{array}$ & Total \\
\hline $\begin{array}{l}\text { Associated } \\
\text { values at the } \\
\text { beginning stage }\end{array}$ & $\begin{array}{l}\text { Fairness and } \\
\text { equality }\end{array}$ & $36.8(14 / 38)$ & $15.8(6 / 38)$ & $52.6(20 / 38)$ \\
\cline { 2 - 5 } & $\begin{array}{l}\text { Kindness to the } \\
\text { first grader }\end{array}$ & $15.8(6 / 38)$ & $31.6(12 / 38)$ & $47.4(18 / 38)$ \\
\cline { 2 - 5 } & Total & $52.6(20 / 38)$ & $47.4(18 / 38)$ & $100.0(38 / 38)$ \\
\hline
\end{tabular}

Table 12.4 Students who transformed their social values and their reasons

\begin{tabular}{l|l|l}
\hline Name & Transformation & Reason for the transformation \\
\hline U.K. & To K.U.'s idea & The first grader will be happy and come here again \\
\hline T.M. & To K.U.'s idea & It is good for us to give a bonus to the first grader \\
\hline N.M. & To K.U.'s idea & It is good for us to be kind to the first grader \\
\hline K.U. & To T.R.'s idea & I think that it is nice to give 2 points because of equality \\
\hline
\end{tabular}




\subsection{Discussion}

Three key points arise from the above results and are emphasized here. Firstly, some social values are implicit. Mathematics has historically been regarded as culturefree and value-free (Bishop 1991). Through its characteristics of abstraction and symbolization, it loses the original context and becomes free from such contexts and values. Such abstractness can be a source of power for mathematics, and thus mathematics can be applied to many different contexts. On the other hand, students in solving the above 'Matoate' problem provided various mathematical models and the social values associated with the models. Indeed students argued that the social value, which gave rise to the mathematical model, becomes a reason for the model. Nevertheless the mathematical model and social value are quite separate and should not be conflated, although they are associated entities. Although it is important for students to be conscious of this reasoning and thus social values, these data also revealed some social values were rather implicit. In order to make these implicit social values explicit, the teacher entered into quite a discussion with the students. In other words, the teacher was quite conscious of the possibility that the social values embedded in the problem may well be quite implicit for some students.

Secondly, let us consider the relationship between this pedagogical approach and mathematical literacy. It is an important task to develop a model to interpret mathematically the phenomenon represented by a problem. If we are satisfied with simply introducing daily phenomena in problem-solving, then we may fall into the same limitations as LUL. On the other hand, if we were to focus only on understanding the mathematical structure, it is just like the mathematics modernization movement. Today we live in a society and age in which we are exposed to significant change caused by technological advancement and globalization of the economy and society. On the one hand, this means that our options often increase. Whereas, on the other hand, various and sometimes opposing social values are produced. In such a context, it is important for students to know there are a variety of social values that can be elicited by a social context, and for them to be able to state their social value(s) associated with a mathematical model and to understand that others' may well choose different models and their associated social values. Using socially open-ended problem offers such an opportunity, where students are placed in a context to develop mathematical models associated with their social values, and also to discuss the possibility of different models and social values. This is precisely the sort of competence being promoted through mathematical literacy.

Thirdly, it is worth considering the transformation of mathematical models and social values through discussion. In the example taken here, refinement of students' thinking regarding mathematical models were observed by comparing those at the beginning and the summary stages of the lesson. On the other hand, value transformation is a little more complicated. We observed that about one third $(31.6 \%)$ of students had been influenced by other students' mathematical models and the associated social values (see Table 12.3), and thus selected different social values at the beginning and the summary stages. In other words, two thirds have not changed their 
values. We think that even among those who have selected the same social values, some may have transformed a little within the same category, by adjusting the mathematical model and/or social value. It may have also been that some students who did not change their choice became more convinced of their original position, although we have no data that speaks to that possibility. Besides, both social values "kindness to the specific person" and "fairness to the whole group" are equally important, and we actually see their application in our daily life. In fact, social welfare should adopt both aspects at a certain level. Therefore, this pedagogical approach requires that the students will be exposed to multiple social values for a long period, understand the difficulty and importance of the coexistence of different social values, and thus discuss the models and social values deliberately, logically, and critically. It is in this context that a new value, which puts emphasis on coexistence of different values, will be created at the meta-level. A future issue is to engage with the long-term transformation of values and development of practices in secondary education through socially open-ended problems.

\section{References}

Baba, T. (2007). Primary mathematics education in a society and times with multiple values. Journal of Japan Society of Mathematics Education, 89(10), 20-27. (In Japanese).

Baba, T. (2009). Analysis of socially open-ended problems in mathematics education from the perspective of values. Journal of Japan Academic Society of Mathematics Education Research in Mathematics Education, 16, 247-252. (In Japanese).

Becker, J. P., \& Shimada, S. (Ed.). (Translated in 1997). The open-ended approach in mathematics education: A new proposal for teaching mathematics. Reston: National Council of Teachers of Mathematics.

Bishop, A. (1991). Mathematical enculturation: A cultural perspective on mathematics education. Dordrecht: Kluwer Academic Publishers.

Clarkson, P. C., Bishop, A., Seah, W. T., \& FitzSimons, G. (2001). An undervalued legacy of mathematics education. In G. FitzSimons, J. O’Donoghue, \& D. Coben (Ed.), Adult and lifelong education in mathematics (pp. 47-70). Melbourne: Language Australia.

Greer, B. (2007). Sense of proportion for social justice. Philosophy of Mathematics Education Journal, 21. http://people.exeter.ac.uk/PErnest/pome21/.

Hashimoto, Y. (2007). Eliciting mathematical ideas from students: Towards its realization in Japanese curricula. In H. Fujita, Y. Hashimoto, B. R. Hodgson, P. Y. Lee, S. Lerman, \& T. Sawada (Eds.), Proceedings of the Ninth International Congress on Mathematical Education (pp. 133-134). Dordrecht: Kluwer Academics Publisher.

Iida, S., Yamashita, A., Sumi, M., \& Komori, A. (1994). Research on recognition of values in open end problem in mathematics education (1): Summary and preliminary report. Research Journal on Kyushu Mathematics Education, 1, 32-43. (In Japanese).

Kobayashi, T. (2007). Era of trans-science: Connecting science and technology with society. Tokyo: NTT Press. (In Japanese).

Kubo, S. (1951). Academic achievement and intelligence test: Higher grades at elementary school in Yokohama city in Showa 24. Tokyo: Tokyo University Cooperative Press. (In Japanese).

Lesh, R., \& Zawojewski, J. (2004). Problem solving and modelling. In F. K. Lester (Ed.), Handbook of research on mathematics teaching and learning (2nd ed., pp. 763-804). Charlotte, NC: Information Age Publishing. 
Ministry of Education, Science and Culture. (1947). Course of study for primary and secondary school (Draft). Tokyo: Ministry of Education, Science and Culture.

Ministry of Education, Science and Culture. (1958). Course of study for primary and secondary school. Tokyo: Ministry of Education, Science and Culture.

Ministry of Education, Science and Culture. (1989). Course of study for junior secondary school. Tokyo: Ministry of Education, Science and Culture.

Nakajima, K. (1981). Mathematical thinking at primary and secondary mathematics education: Consideration of its development. Tokyo: Kaneko Shobo. (In Japanese).

National Institute for Education Research (NIER). (1991). International comparison of mathematics education-The final report of second international mathematics study. Tokyo: Dai-ichi-Houki. (In Japanese).

Nagasaki, E. Shimada, I., \& Nishimura, K. (2008). Study on the refinement of the structure of the power to connect mathematics and society. In Proceedings of the 41st Annual Conference of Japan Society of Mathematics Education (pp. 231-236). Tokyo: Japan Society of Mathematics Education. (In Japanese).

OECD. (2013). PISA 2012 assessment and analytical framework: Mathematics, reading, science, problem solving and financial literacy. Paris: OECD Publishing.

Palm, T. (2008). Impact of authenticity on sense making in word problem solving. Educational Studies in Mathematics, 67, 37-58.

Schoenfeld, A. (1983). Beyond the purely cognitive: Belief systems, social cognitions, and metacognitions as driving forces in intellectual performance. Cognitive Science, 7, 329-363.

Shimada, S. (Ed.). (original version 1977, new version 1995). Open-ended approach in mathematics. Tokyo: Toyo-kan shuppan. (In Japanese).

Shimada, I., \& Baba, T. (2012). Emergence of students' values in the process of solving the socially open-ended problem. In T. Y. Tso (Ed.), Proceedings of the 36th Conference of the International Group for the Psychology of Mathematics Education (Vol. 4, pp. 75-82). Taipei, Taiwan: PME.

Shimada, I., \& Baba, T. (2016). Transformation of students' values in the process of solving socially open-ended problems: Focusing on long-term transformation. In C. Csikos, A. Rausch, \& J. Szitanyi (Eds.), Proceedings of the 40th Conference of the International Group for the Psychology of Mathematics Education (Vol. 4, pp. 187-194). Szeged, Hungary: PME.

Skovsmose, O. (1994). Towards a philosophy of critical mathematics education. Dordrecht: Kluwer Academic Publishers.

Toda, K. (Ed.). (1953). Learning mathematics grade 6. Tokyou: Gakkou-Tosho.

Ueda, A., Baba, T., \& Matsuura, T. (2015). Values in Japanese mathematics education from the perspective of open-ended approach. Teaching Innovations, 27(3), 69-82.

Open Access This chapter is licensed under the terms of the Creative Commons Attribution 4.0 International License (http://creativecommons.org/licenses/by/4.0/), which permits use, sharing, adaptation, distribution and reproduction in any medium or format, as long as you give appropriate credit to the original author(s) and the source, provide a link to the Creative Commons license and indicate if changes were made.

The images or other third party material in this chapter are included in the chapter's Creative Commons license, unless indicated otherwise in a credit line to the material. If material is not included in the chapter's Creative Commons license and your intended use is not permitted by statutory regulation or exceeds the permitted use, you will need to obtain permission directly from the copyright holder.

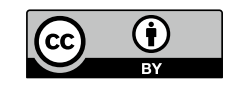

